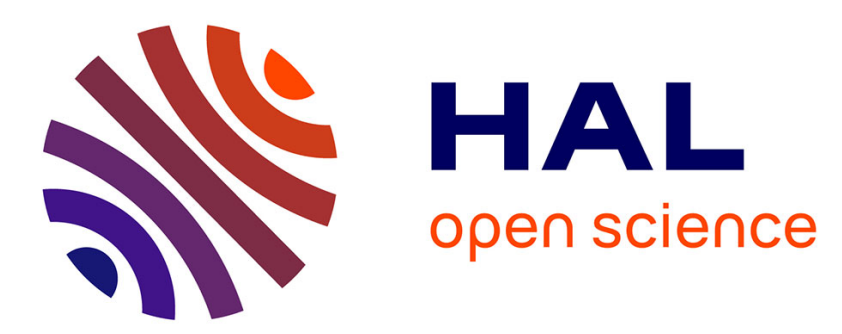

\title{
Control of DC bus voltage with a Modular Multilevel Converter
}

\author{
Shabab Samimi, François Gruson, Xavier Guillaud, Philippe Delarue
}

\section{To cite this version:}

Shabab Samimi, François Gruson, Xavier Guillaud, Philippe Delarue. Control of DC bus voltage with a Modular Multilevel Converter. Powertech2015, Jun 2015, Eindhoven, Netherlands. pp.00, 10.1109/PTC.2015.7232570 . hal-03170455

\section{HAL Id: hal-03170455 \\ https://hal.science/hal-03170455}

Submitted on 16 Mar 2021

HAL is a multi-disciplinary open access archive for the deposit and dissemination of scientific research documents, whether they are published or not. The documents may come from teaching and research institutions in France or abroad, or from public or private research centers.
L'archive ouverte pluridisciplinaire HAL, est destinée au dépôt et à la diffusion de documents scientifiques de niveau recherche, publiés ou non, émanant des établissements d'enseignement et de recherche français ou étrangers, des laboratoires publics ou privés. 


\section{Control of DC bus voltage with a Modular Multilevel Converter}

\author{
S. Samimi L2EP, Ecole Centrale de Lille, 59650 Villeneuve \\ d'Ascq, France shabab.khorgami@ec-lille.fr, \\ F. GRUSON, L2EP, Arts et Métiers ParisTech, 8, Bd Louis \\ XIV, 59046 Lille, France francois.gruson@ensam.eu
}

\author{
X. Guillaud L2EP, Ecole Centrale de Lille, 59650 Villeneuve \\ d'Ascq, France xavier.guillaud@ec-lille.fr \\ P. DELARUE' L2EP, LiLle1 UNIVERSITY, 59655 VilleNEUVE \\ D’ASCQ, FRANCEPHILIPPE.DELARUE@,UNIV-LILLE1.FR
}

\begin{abstract}
Modular Multilevel Converters (MMC) are becoming increasingly popular with the development of HVDC connection and, in the future, Multi Terminal DC grid. A lot of publications have been published about this topology these last years since it was first proposed. Few of them are addressing explicitly the two different roles that are held by this converter in a HVDC link: controlling the power or controlling the DC voltage level. Most of the time, the DC-bus voltage is supposed to be constant. In an HVDC link, this corresponds to the substation which controls the power. This paper addresses the cases when the voltage is regulated by the converter and presents the different ways of voltage control.
\end{abstract}

Index Terms- Electromagnetic Transients program (EMTP), HVDC DC bus control, Modular Multilevel Converter (MMC), MMC current and power controls.

\section{INTRODUCTION}

HVDC link are expected to a large development due to the increasing need to transmit electrical power. Many projects have been developed in this field till now mainly in the classical thyristor technology. Other projects are now under development transistor technology thanks to the use of modular multilevel converter (MMC) which is the most promising topologies for these type of applications.

A great number of published papers have been focused on the complex control topology for this converter with a large number of variables. Different levels of control may be distinguished from the lowest control of the switches, balancing of the voltage of each sub-module to the control of the overall energy in the MMC. Some papers have been focused on the control of the currents such as in [1], and the control of the energy such as in [2], [3]. Many control structures have been proposed in order to accomplish these tasks. Moreover the studied control methods have been proposed where the MMC is in an HVDC or back to back configuration [4], [5]. Some of the controls presented in the literature have in common to be introducing by a heuristic way. One consequence is that these different controls have not the same number of controllers. But, to have a fully control of the energy stored in the system, the number of controllers must be equal to the number of independent state variables of the system. If not, some state variables may be out of control, can take unacceptable values and lead to unstable modes in particular operating conditions.
However, in these articles, the DC-bus voltage is imposed on sub-module capacitor voltages and few of them are addressing explicitly the two different roles that are hold by this converter in a HVDC link: controlling the power or controlling the DC voltage level. This paper recalls the fundamentals for the control of energy stored in a MMC which can be achieved either by the AC power grid or the DC power. For a substation controlling the power, the choice operated at this level may be neutral. For a substation controlling the voltage, the paper shows that this choice may induce critical consequence in term of expected variation of voltage. Indeed, contrary to the classical VSC, the storage element is not directly connected on the DC-bus so the exchange of power between the stored energy and the DC-bus has to be studied very carefully to quantify the storage level really available on the DC-bus.

\section{MMC MODELLING}

\section{A. Arm Average Model}

Fig. 1 recalls an equivalent model of the converter [6] where each arm is composed of dozens or hundreds of submodules which have been replaced by an equivalent model composed of a chopper and an equivalent capacitor. The voltage $\left(v_{\text {cui tot }}, v_{\text {cli tot }}\right)$ applied on this capacitor is the sum of all the voltages of each sub-module.

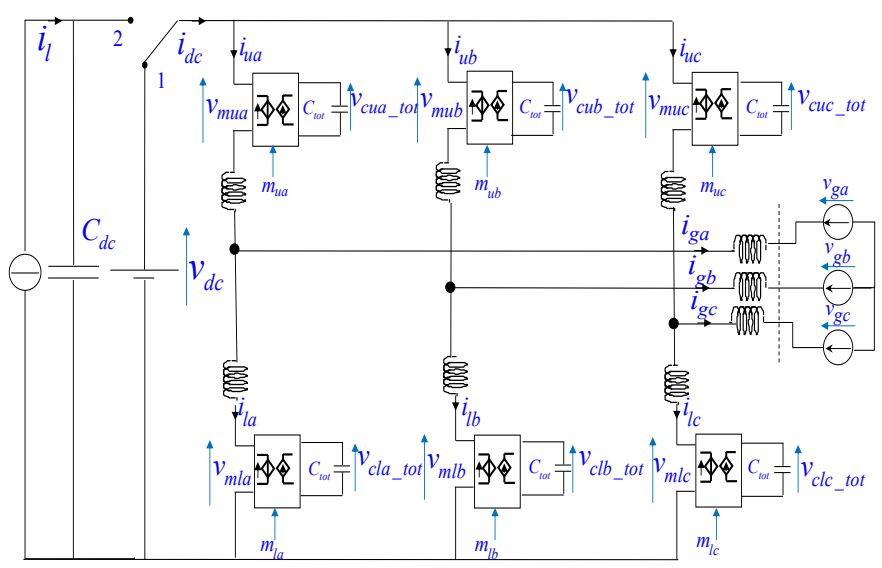

Figure 1: Equivalent circuit configuration of the MMC

In this figure, two topologies are proposed depending on the position of the selector. In position 1, the dc bus is imposed to the MMC which means that the converter may 
only control the power. In position 2 , the $\mathrm{DC}$ bus is represented by a capacitor and a current source. The DC-bus voltage has to be controlled. The current source is a simple model of the power which is managed by the converter placed on the other side of the HVDC link.

From this equivalent topology, it is possible to define an equivalent model which is very useful for the design of the two current controllers: control of the AC current, control of the DC current [7], [8].

\section{B. Energetic model}

Assuming that the current control is achieved, another level of model is needed to design the energy control. The total energy $\left(W_{i}\right)$ in a leg is defined such as:

$$
W_{i}=\frac{1}{2} C_{t o t}\left(v_{\text {cutot } i}^{2}+v_{\text {cltot } i}^{2}\right)
$$

As discussed in [2], the variation of $W_{i}$ is depending on the instantaneous $\mathrm{AC}$ power of the phase $i, p_{A C} i$, and the power exchanged with the DC bus $p_{D C} i$ which depends on the DC component of the differential current.

$$
\frac{d W_{i}}{d t}=\frac{1}{2} C_{t o t}\left(\frac{d v_{c u t o t i}^{2}}{d t}+\frac{d v_{c l t o t i}^{2}}{d t}\right)=p_{D C i}-p_{A C i}
$$

The expression of the whole $\mathrm{AC}$ power is given by equation (3)

$$
p_{A C}=v_{g d} \cdot i_{g d}
$$

Where $v_{g d}$ and $i_{g d}$ are the $\mathrm{d}$ components of the grid voltage and the grid current. The AC power on phase ' $i$ ' is considered to be one third of the whole power:

$$
p_{A C i}=\frac{p_{A C}}{3}
$$

The DC power on phase ' $\mathrm{i}$ ' is given by (5)

With:

$$
p_{D C i}=v_{d c} \cdot i_{d i f f i}
$$

$$
i_{\text {diff } i}=i_{u i}+i_{l i}
$$

These different equations may be presented on a block diagram (upper part of Fig. 2)

In term of control, equation (2) highlights that the energy may be controlled either by means of AC power or DC power. Depends on the chosen solution the role of the grid current and differential current are exchanged. This issue is discussed and is simulated in [7] .

\section{POWER CONTROL IN CASE OF CONSTANT DC BUS VOLTAGE}

\section{A. Energy controlled by the DC power}

In this solution, the energy is supposed to be controlled by the DC power. $v_{\text {ctoti }}$ is defined as :

$$
v_{c t o t i}^{2}=\frac{v_{c u t o t i}^{2}+v_{c l t o t i}^{2}}{2}
$$

Three independent control loops for each $v_{\text {ctot } i}$ have been implemented. These three loops define the three references for each differential current so exchange of power between the MMC and the DC bus. As it can be sketched on Fig 2, the architecture of the control is deduced by the inversion of the model of the process. Since $p_{A C} i$ is a disturbance, a compensation term is implemented in the control. A filter has to be inserted on the voltage measurement to avoid introducing harmonics in the generation of the reference.

The power flowing through the converter is imposed by the reference on AC power $\left(P_{A C r e f}\right)$..

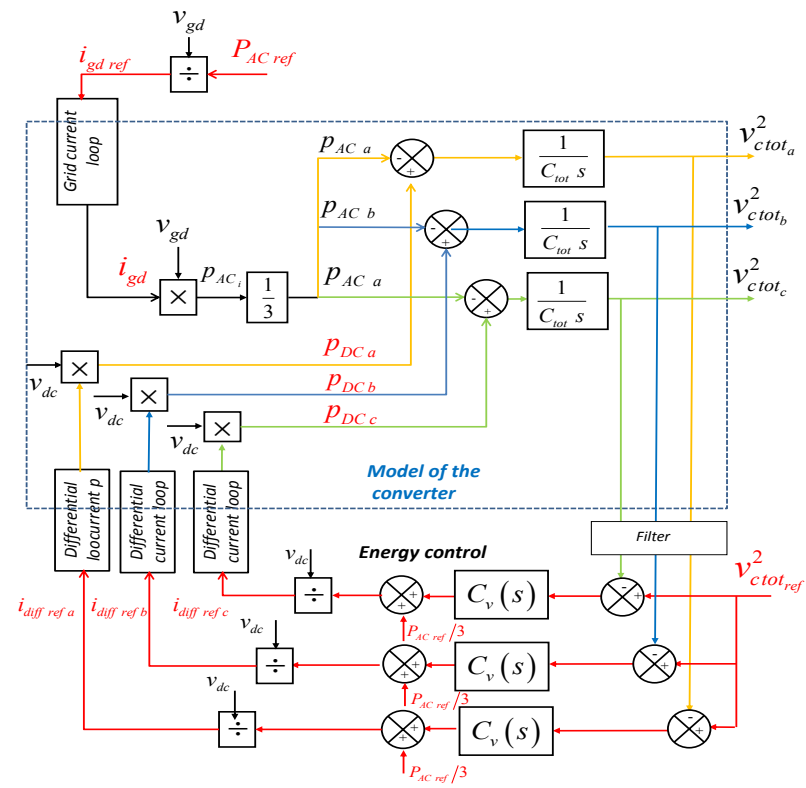

Figure 2: Energy control by DC power

\section{B. Energy controlled by the AC power}

When analysing equation (2), it can be seen that another solution is to control the energy with AC power.

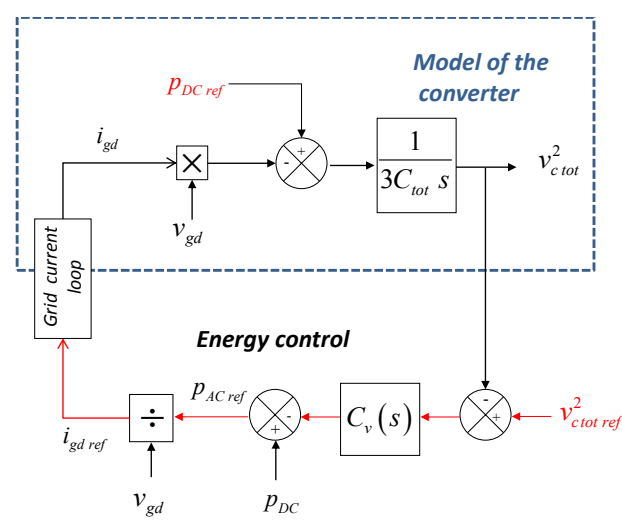

Figure3: Energy control by AC power 
In this control scenario the power flowing through the converter is imposed by the reference on DC power $\left(P_{D C}\right.$ ref $)$. Since the sum of the three currents is always null, it is not possible to implement three separate grid current loops. This induces that only a global control of the whole energy stored in the MMC is possible.

\section{POWER CONTROL IN CASE OF VARIABLE DC BUS VOLTAGE}

As explained in the introduction, in HVDC applications it is also needed to achieve the control of the station which is controlling the DC-bus voltage. Contrary to the voltagesource converters (VSC), the voltage applied to MMC capacitors is not the same as the DC bus voltage. Hence, there is no relation between the stored energy inside the converter and the DC-bus voltage. The aim of following section is to establish a link between both thanks to the control.

\section{A. Model of the system}

Since the DC-bus voltage is not constant (switch in Fig.1 on position2), the model of the system has to be adapted to take into account the behaviour of the DC bus. The variation of the stored energy in the DC capacitor $C_{d c}\left(W_{D C}\right)$ is depending on the power exchanged by the MMC $p_{D C}$ with the DC bus and the power flowing from the other substation $p_{l}$.

$$
\frac{1}{2} C_{d c} \frac{d v_{d c}^{2}}{d t}=\frac{d W_{D C}}{d t}=-p_{D C}+p_{l}
$$

With: $\quad p_{D C}=\sum_{i=1}^{3} p_{D C}$

The new model of the converter is presented in Fig. 4.

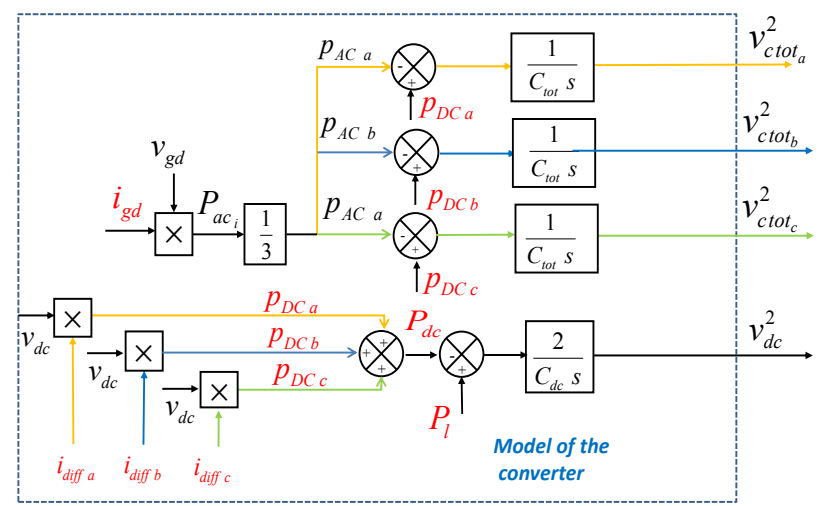

Figure4: MMC block diagram with DC bus model

\section{B. The two Solutions for the energy control.}

In the previous section two ways of energy control have been presented. In both cases the level of the stored energy is constant. In order to establish a relation between the energy in the converter capacitors and the DC-bus voltage level, a link may be established between the reference of MMC capacitors $V_{\text {ctot ref }}$ and the DC-bus voltage $V_{D C}$ converter .Two cases will be considered:

Case1: $V_{c \text { tot }}^{2}=1 \mathrm{pu}$

Case 2: $V_{c \text { tot }}^{2}=V_{d c}^{2}$
Since there are two solutions to control the energy, four cases are studied and simulated. All model developments and simulation are performed using EMTP ${ }^{\mathrm{RV}}$ [9]. Simulated parameters can be found in index I.

\section{1) Energy controlled by the DC power}

In this scenario of control the power flowing through the converter is imposed by $P_{A C \text { ref. }}$ In all the following equations, the value of $V_{\text {ctot } i}^{2}$ is supposed to be equal to its reference $V_{\text {ctot ref. }}^{2}$. Moreover, the $\mathrm{AC}$ power $P_{A C}$ is also supposed to be equal to its reference $P_{A C \text { ref }}$. Adding the set of three equations (2) leads to the following equation:

With:

$$
\begin{gathered}
\frac{d W_{t o t}}{d t}=\frac{1}{2} C_{t o t}\left(6 \frac{d v_{c t o t r e f}^{2}}{d t}\right)=p_{D C}-P_{A C \text { ref }} \\
v_{c t o t}^{2}=\sum_{i=1}^{3} v_{c u i_{-} t o t}^{2}+\sum_{i=1}^{3} v_{c l i \_t o t}^{2}
\end{gathered}
$$

In case $1 V_{\text {ctot ref }}^{2}$, is constant, which leads to the equality between $P_{D C}$ and $P_{A C \text { ref }}$. Equation (8) can be written as:

$$
\frac{1}{2} C_{D C} \frac{d v_{d c}^{2}}{d t}=-P_{A C \text { ref }}+p_{l}
$$

And in case 2, equation (10) may be written as:

$$
p_{D C}=\frac{1}{2} C_{t o t}\left(6 \frac{d v_{c t o t}^{2}}{d t}\right)+P_{A C \text { ref }}
$$

Merging this equation (13) with equation (8) leads to:

$$
\frac{1}{2}\left(6 C_{t o t}+C_{D C}\right) \frac{d v_{D C}^{2}}{d t}=-P_{A C \text { ref }}+p_{l}
$$

This equation shows that the MMC behaves as if the six capacitors were on the DC-bus which was the aim to achieve. In other words, the MMC behaves as a VSC with a capacitor of $\mathrm{C}_{\mathrm{DC}}+6 \mathrm{C}_{\text {tot }}$. The simulation results presented in Fig.6 confirm this assertion. cases.

Fig.5 shows the equivalent block diagram in the two
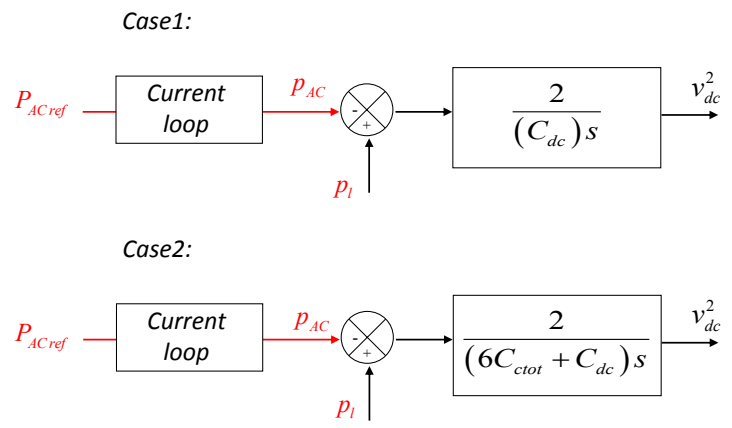

Figure 5: Energetic model of the MMC and the DC-bus energy control by $p_{D C}$ 
At $\mathrm{t}=0.1 \mathrm{~s}$, a step of -0.004 pu on $P_{A C \text { ref }}$ is applied during $300 \mathrm{~ms}$.

a)

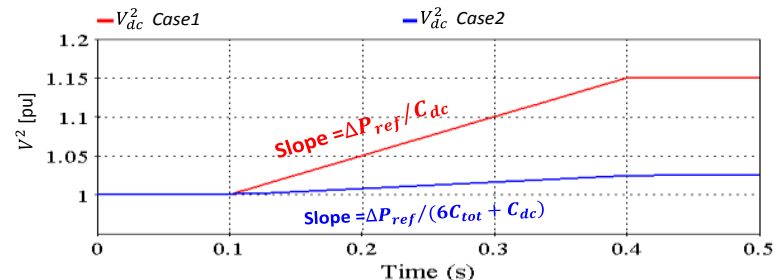

b)

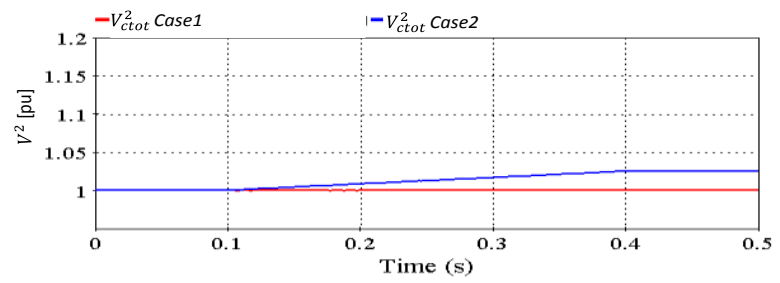

c)
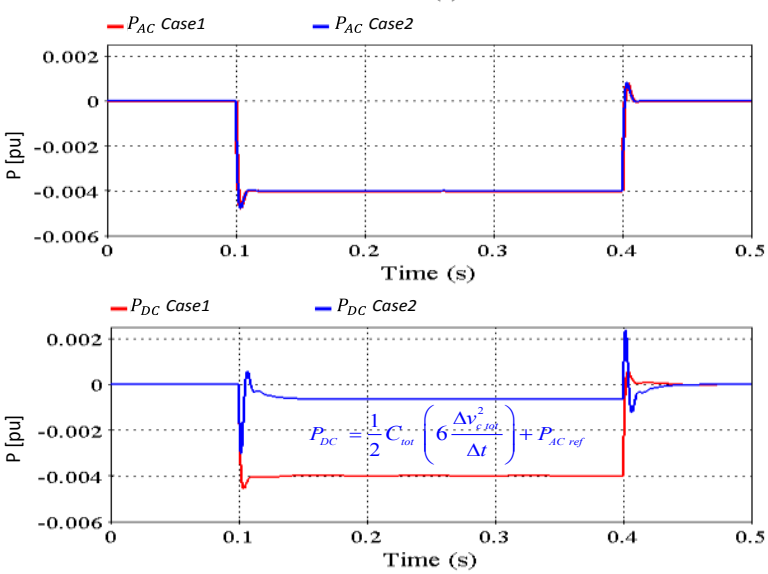

Figure 6 : Energy controlled by the DC power in two cases:

$$
\text { Case } 1: V_{c t_{\text {tot }}}^{2}=\text { constant and case } 2: V_{c t_{\text {tot }} \text { ref }}^{2}=V_{D C}^{2}
$$

Since $p_{l}$ is not changed, $v_{D C}$ is increasing. For case 1 , the energy is constant (Fig.6 b), $p_{D C}$ ( Fig.6 c) and $P_{A C \text { ref }}$ ( Fig.6 d) are equal in steady state. The slope of $v_{D C}$ is derived from equation (12) where only $C_{D C}$ is involved.

In case 2 , the slope of $v_{D C}^{2}$ is much smaller since it is derived from the equation (14) where $C_{C t o t}$ is involved. $p_{D C}$ is not equal to $P_{A C \text { ref }}$ as shown on Fig. 6 c. In steady state, the difference is explained by equation (13).

2) Energy controlled by the AC power

With this type of control, regarding to section III, the power flowing through the converter is imposed by the $P_{D C \text { ref, }}$, equation (8) is changed as following:

In steady state $p_{D C}$ is supposed to be equal to $P_{D C \text { ref }}$ :

$$
\frac{1}{2} C_{D C} \frac{d v_{D C}^{2}}{d t}=-P_{D C r e f}+p_{l}
$$

The energetic model is the same in both cases. It is shown in Fig.7.

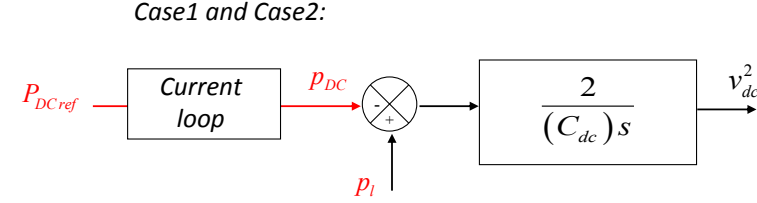

Figure 7: Energetic model of the MMC and the DC bus energy control by $P_{D C}$

Since the energy stored in the MMC comes from the AC grid, the AC power is deduced from the DC power. In case2, it can be written:

$$
p_{A C}=P_{D C \text { ref }}-\frac{1}{2} C_{t o t}\left(6 \frac{d v_{d c}^{2}}{d t}\right)
$$

Like in the previous section, this solution is studied with the two cases and the simulation results are compared in Fig.8.

At $\mathrm{t}=0.1 \mathrm{~s}$, a step of $-0.004 \mathrm{pu}$ on the DC power is applied during $300 \mathrm{~ms}$.

a)

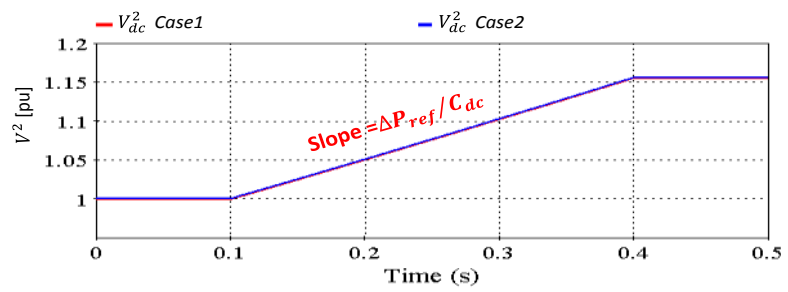

b)

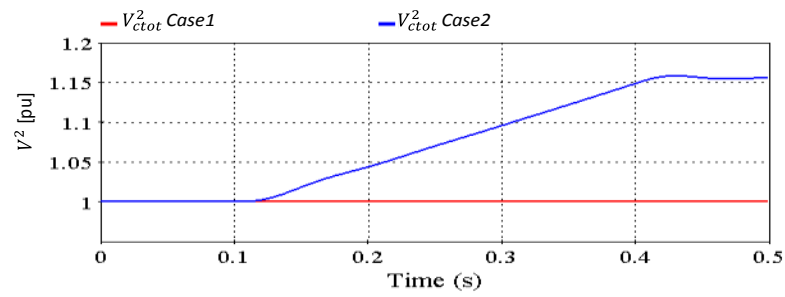

c)
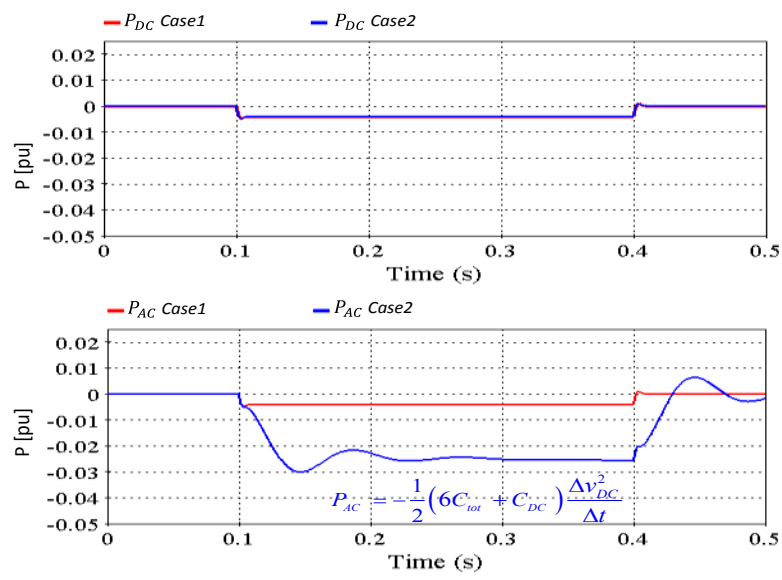

Figure 8 : Energy controlled by the AC power in two cases:

Case $1: V_{c \text { tot } t_{r e f}}^{2}=$ constant and case $2: V_{c t o t_{r e f}}^{2}=V_{d c}^{2}$

As it is depicted in Fig.8a, and contrary to the first control solution, the dynamic of DC-bus voltage in both cases is the same and it only depends on $C_{D C}$. It is understandable because in both cases, the $p_{D C}$ power is the same. 
The only difference is noticed on $p_{A C}$. In case $1, P_{A C}$ is constant, in case 2 , it is depending on the slope of the DC-bus voltage. It is possible to verify equation (16) in steady state.

\section{Voltage control}

In this section, the impact of the choice operated on the energy control is evaluated on the DC-bus voltage control. Only the solution of energy controlled by $p_{D C}$ is analyzed.

In Fig.8, the whole block diagram is presented. Since the energy is controlled by the DC power, the DC-bus voltage is controlled by AC power. Variation on DC-bus voltage are induced by variations on $p_{l}$.

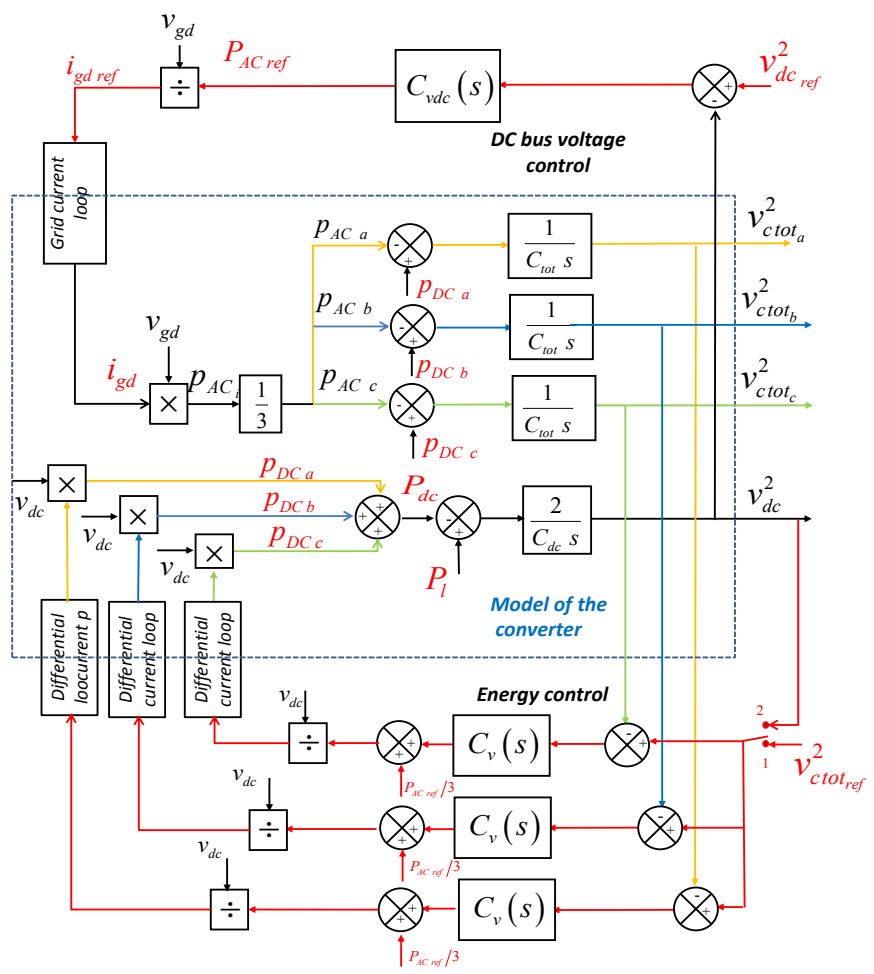

Figure 9: Control of DC bus voltage - Model and control loops.

The influence of the choice on the reference of energy (case1, case2) is investigated. Fig.10 presents the simulation results in case1. A step of .1(pu) on the $p_{l}$ is applied at $\mathrm{t}=0.1 \mathrm{~s}$

a)

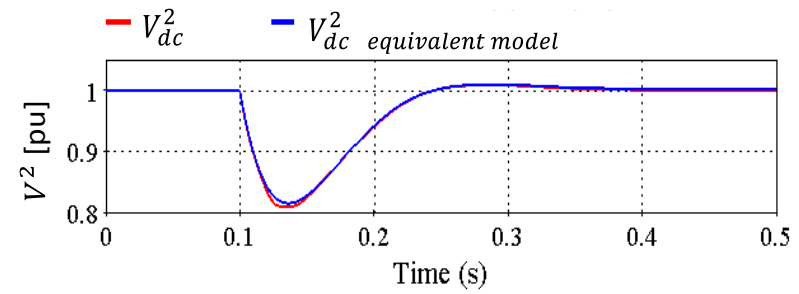

b)

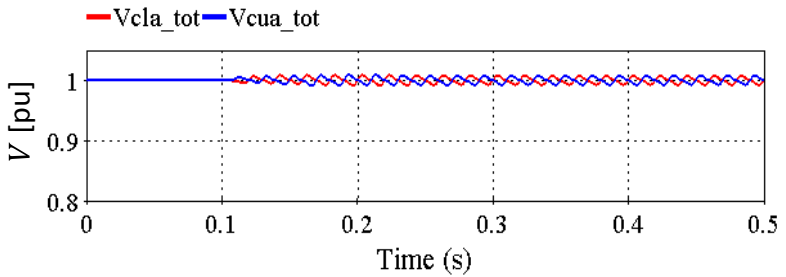

Figure 10: Comparison of model equivalent with Control of DC-bus voltage for case 1
Results from the whole model (Fig.9) and equivalent model (Fig.5) are compared. Fig.10a shows the voltage drop, consequence of the step on $p_{l}$. In Fig.10b it can be seen that the stored energy in MMC is staying constant and is not depending on the DC-bud voltage level.

In case2,the stored energy in the MMC is depending on the DC-bus state so as shown previously, the equivalent capacitor on the DC-bus is much higher. For the same events as previously (step of $0.1 \mathrm{pu}$ at $\mathrm{t}=0.1 \mathrm{~s}$ ), the voltage drop is much smaller as seen on Fig 11a. Fig.11b confirms that the stored energy is clearly depending on the DC-bus voltage.

a)

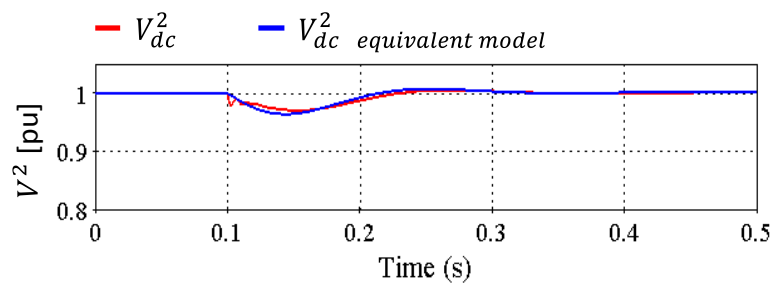

b)

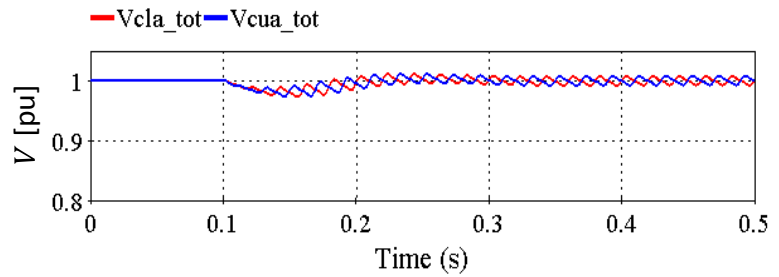

Figure 11: Comparison of model equivalent with Control of DC bus voltage for case 2

\section{CONCLUSION}

This paper has presented different solutions to control a MMC connected to DC bus whose voltage is varying. Two solutions of control are emerging from the definition of the energy model: control of the energy by the AC power $t$ or the DC power. Depending on the chosen solution the exchange of power between the MMC and the AC or DC grid is different. A solution to have the inside stored energy participating linked to the DC voltage bus has been proposed. This desirable property may have important impact on the stability of the control of the DC voltage of a HVDC. Also this solution may be extended to the control of a Multi Terminal DC grid.

\section{REFRENCES}

[1] Q. Tu, Z. Xu et L. Xu, «"Reduced Switching-Frequency Modulation and Ciculating Current Suppression for Modular Multilevel Converters",» Power Delivery,IEEE Transactions, 2011.

[2] P. Delarue, F. Gruson et X. Guillaud, «"Energetic Macroscopic Representation and Inversion Based Control of a Modular Multilevel Converter”,» EPE 2013 - Lille, France.

[3] G. Bergna, P. E. Berne, P. Lefranc, A. Arzandé, J.Vannier et M.Molinas, «"An Energy-based Controller for HVDC 
Modular Multilevel Converter in Decoupled Double Synchronous Reference Frame for Voltage Oscillations Reduction",» IEEE Transactions on Industrial Electronics, 2012..

[4] M. Saeedifard et R. Iravani, “"Dynamic performance of a modular multilevel back-to-back HVDC system,",» IEEE Trans. Power Del., vol. 25,no. 4, pp. 2903-2912, Oct. 2010.

[5] G. Bergna, M. Boyra et a. J. H. Vivas, «"Evaluation and proposal of MMC- HVDC control strategies under transient and steady state conditions,",» in Proc. Eur. Power Electron. Conf., Birmingham, U.K., 2011,pp. 110.

[6] J. Peralta, H. Saad, S. Dennetière, J. Mahseredjian et S. Nguefeu, «"Detailed and averaged models for a 401-level MMC-HVDC system,'IEEE Trans. Power Del., vol. 27, no. 3, pp. 1501-1508, Jul. 2012.».

[7] S.Samimi, F.Gruson, P.Delarue et X. Guillaud, «"Synthesis of Different Types of Energy Based Controllers for Modular Multilevel Converter integrated in an HVDC Link",» ACDC Conference,Feb. 2015.

[8] Y. Zhang, Q. Ge, R. Zhang et Y. Du, «"The control of arm currents and the parameters for modular multilevel converters",» porc.15th Int . Electrical Machines and systems(ICEMS) Conf,2012.

[9] J. Mahseredjian, S. Dennetière, L. Dubé, B. Khodabakhchian et a. L. Gérin-Lajoie, «"On a new approach for the simulation of transients in power systems",» Elect. Power Syst. Res.,vol. 77,no.11,pp.15141520,Sep. 2007..

\section{Index I:}

System parameters:

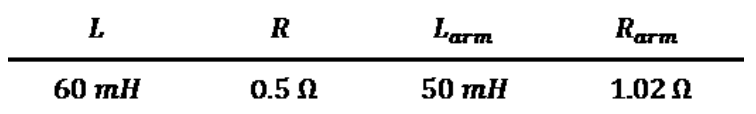

\begin{tabular}{ccccc}
$C_{\text {tot }}$ & $C_{d c}$ & $S_{n}$ & $V_{d c}$ & $U_{g}$ \\
\hline $10 \mathrm{mF}$ & $39 \mu \mathrm{F}$ & $1000 \mathrm{MVA}$ & $640 \mathrm{kV}$ & $320 \mathrm{kV}$
\end{tabular}

Settling times for control loops:

\begin{tabular}{cccc}
$T_{r_{-} i g}$ & $T_{r_{-} \text {idiff }}$ & $T_{r_{-} \text {Wsum }}$ & $T_{r_{-} V d c}$ \\
\hline $5 \mathrm{~ms}$ & $5 \mathrm{~ms}$ & $50 \mathrm{~ms}$ & $100 \mathrm{~ms}$
\end{tabular}

